\title{
How Did Humans, ANimals AND PlaATS ORIGINATE?
}

\author{
Mei Yin
}

Nanjing, China

\begin{abstract}
With black hole explosion under incredibly high temperatures leading to cosmic information billions of years ago, all matters had been in gaseous phase. With temperature dropping, under atomic attractive forces, adjacent atoms which made up gases attracted each other and formed a variety of big, small or tiny gaseous lumps. With the temperature persistently dropping, the tiny gaseous lump became colder and contracted and got smaller and turned into one in liquid state and subsequently in solid state according to the principle of expanding when heated and contracting when cooled in general cases. Gradually it developed and formed a human-or animal-like fetus or a plant-like seed. If it had the same compositions as a human, cow or sunflower, the human, the cow or the sunflower formed. Similar cases happened to other humans, animals and plants. Humans neither evolved from apes nor shared a common ancestor with apes.
\end{abstract}

\section{KEYWORDS}

Origins of humans, animals and plants, cosmic formation, property and counts of brain neuron in language and thinking areas, brain structure, black hole.

\section{INTRODUCTION}

Charles Darwin's theory of evolution was published in 1859 and has been dominant for more than 150 years, indicating that humans evolved from apes (Hale, 2012, Johnson, 2001). However, some studies demonstrated that humans shared a common ancestor with apes, but did not evolve from apes (e.g., Christensen, 2001, White et al., 2009). Recent neuroscience research showed that the human brain was organized differently from the ape brain (Premack, 2007, Holloway et al., 2009). In 1999 Preuss and Coleman's microscopic study first demonstrated that "In one layer of the human primary visual cortex, nerve cells were organized in a complex meshlike pattern very different from the simpler vertical arrays of cells in other primates." which was noted by Premack (2007, p. 13861). These studies demonstrated different points of view or possibilities concerning the origin of human life. How did human life actually originate? Besides, it remains unknown regarding origins of animals and plants. The atomic structures of the cell were discovered in the 20th century (Johnson, 2001) and the cosmic formation theory was just built (Yin, 2020). That is to say that in the Darwin's era, the atomic structures of the cell had not been discovered until the 20th century and the cosmic formation theory had not been built until recently and the microscopic study of human brains in the field of neuroscience had not started until 1999. With appearances of these new scientific discoveries and theories in the last more than one hundred years, it is significant to make new scientific research on origins of human life from a brand new perspective and on origins of animals and plants which are still gaps needing filling. The paper aims to clarify when and how humans, animals and plants originated and whether humans evolved from apes or shared a common ancestor with apes by providing a new theoreticallybased analysis and explanations or a new theoretical point of view based on comic formation David C. Wyld et al. (Eds): AIAP, IT, MoWiN, CCSEIT, CNSA, ICBB - 2022 pp. 119-136, 2022. CS \& IT - CSCP 2022 
theory, hereditary theory and related physical and chemical theories including atomic motion theory, electromagnetic field theory, atomic and molecular structure formation theory.

\section{How did Lives of Humans, Animals and Plants Originate?}

Billions of years ago the black hole exploded under incredibly high temperatures (Hawking, 1974), which led to the birth of the universe on the basis of the cosmic formation theory (Yin, 2020). Simultaneously non-life forms of all life started to appear. That indicated that the earliest non-life forms of all life were born together with the non-life forms of stars (e.g., the Sun), planets (e.g., the earth, the mars), etc. at the beginning of the universe. All solid (e.g., metal, rock, wood, glass) and liquid (water, alcohol, etc.) matters spewing out of the black hole had been vaporized or in gaseous phase besides those original gases also from the black hole (Yin, 2020). All these gases contain compositions which make up all non-life matter (e.g., water, air) and objects (e.g., stars, planets) (Yin, 2020) and all forms of life (humans, animals, plants) in the universe. When all these gaseous matters spewed out of the black hole, they instantly scattered to all over the universe (Yin, 2020). Now we see that the universe is filled with stars, planets, asteroids, etc. Actually at that time the universe was also full of various non-life forms of life. However, survival of life was much more difficult and an individual life is much shorter, just as if it exists just for an instant compared with non-life matter and most of objects.

With temperature dropping, adjacent atoms which made up gases attracted each other and formed a big or small gaseous lump (Yin, 2020). The electromagnetic field theory indicates that opposite magnetic poles and electric charges attract each other and that any atom is a dipole with opposite magnetic poles and positive and negative electric charges (Blehl, 2006, Dorfmann and Ogden, 2014). When the temperature became colder, the gaseous lump also became colder and contracted and got smaller according to the principle of expanding when heated and contracting when cooled in general cases (Yin, 2020). It rapidly turned into one in liquid state and subsequently one in solid state and formed a star- or planet- or asteroid-shaped object (Yin, 2020). If the star- or planet- or asteroid-shaped object had the same compositions of the Sun, the earth or an asteroid, the Sun, the earth or the asteroid was born (Yin, 2020). Similar cases also happened to other stars, planets, asteroids and small and tiny objects (Yin, 2020). As such, the universe is full of all types of stars, planets, asteroids, small and tiny objects which lied in locations close to or far away from each other just as we see numerous stars in the nearby or faroff sky at night on a clear day. Of course, there must be numerous stars, planets, etc that we have not been able to observe or see by using the latest technology which humans have invented or created by now.

Similarly, adjacent atoms which made up gases also attracted each other and formed various extremely small or tiny gaseous lumps. Under atomic attractive forces, adjacent gaseous lumps similarly attracted mutually and connected and fused with one another and formed a bigger gaseous lump. Similar cases also happened to other adjacent gaseous lumps. If some of the gaseous lumps contained complicated atomic and molecular structures or compositions of the fertilized egg cell and related development environment of humans, animals, or plants (e.g., tree, flower, etc.), they made good preparations for the potential appearance of different forms of life. With the temperature persistently dropping, these gaseous lumps became colder and contracted and got smaller according to the principle of expanding when heated and contracting when cooled in general cases. They rapidly turned into ones in solid phase or in a normal state and gradually developed into ones with simple forms of life (human, animal or plant). They continued growing and became bigger just as a fetus curled up in the solid- or ball-like womb or just as a solid- or ball-like seed. If one of them contained the same compositions as a human or cow or sunflower, the human or the cow or the sunflower formed. Obviously, the human or cow embryo and fetus or sunflower seed embryo in the solid- or ball-like shape must have got enough 
nutrients and had suitable temperatures and other necessary environmental conditions for survival, growth and maturity. If the newborn human or cow or sunflower could continue getting enough nutrients and having suitable temperatures and other necessary environmental conditions for survival and growth, the newborn human or cow or sunflower could continue surviving and growing. Similar cases happened to other humans, animals and plants. As such, there were man, woman, various animals and plants in the natural world. We have seen that seeds of flowers, grasses, trees and other plants are in geometric solids (e.g., sphere, oval, and cylinder) just like human and animal embryos and stars, planets, asteroids in geometrical solids (e.g., sphere and oval) despite the difference in width, length, height and weight (e.g., Brunken, de Wet and Harlan, 1977). In any case, only those humans or animals or plants that have the body structure and cell atomic and molecular structures and components which were consistent with the law of life survival and growth could survive and grow in addition to having enough nutrients, suitable temperatures and other necessary environmental conditions for survival and growth. If the body structure and cell atomic and molecular structures or components which were completely or basically inconsistent with the law of life survival and growth, they could not form normal living things like humans, animals or plants. They stopped growing and gradually or immediately died. The Mermaid described in the fairy tale or the Sphinx in Egypt most probably once existed as a natural organism. That is to say that they are most possibly neither made up by our ancestors based on their imagination nor artificial products created by scientists in a high-technology experiment, but once appeared as a natural form of life. Up to now, people still can see a variety of physical deformities in humans, animals and plants. As far as humans are concerned, these physical deformities are varied indeed, serious or not serious so that some of people with physical deformities can still be kept to live a normal life and their life quality and lifespan is not negatively affected by the physical deformities. However, unfortunately some others of them are more or less negatively affected by the physical deformities. They have a short or relatively long lifespan, depending on the severity of the deformity threatening life, whether they can get timely treatments and the status of medical science and technology development. Pantoja Zarza and Diez Morrondo (2014) demonstrated that skeletal and facial deformities in Mucolipidosis III start at the age of 3-5, belonging to genetically metabolic diseases and patients are expected to reach up to the fifth decade of life due to the slow evolution of the disease. Li et al.'s (2012) study revealed that inborn spinal deformities in rat offspring were caused by maternal Vitamin A deficiency, indicating that animals' deformities exist indeed. They noted that there are also other organ deformities, e.g., inborn kidney and heart deformities. Pruyn, Gartner and Harmon (2002) recorded that trees without stem deformities and diseases and broken tops were chosen as samples, indicating that deformities of trees as plants also really exist.

When humans, animals, trees, flowers, grasses or other plants were born, if they fell on the surface of the earth and got sufficient nutrients and suitable temperatures and other necessary environmental conditions for survival and growth, they could continue being alive until they died of illness or other causes. If some of them could not get sufficient nutrients or suitable temperatures or other necessary environmental conditions for survival, they would not survive. If they fell inside the earth, similarly they must have enough nutrients, suitable temperatures and other environmental conditions for survival. If they could get what were required for survival, they could survive. Otherwise, they would die. That indicated that humans, animals, flowers, grasses and trees and other plants could fall not only on the earth's surface but also in different parts inside the earth. They could also fall on and inside and even between other stars, planets, asteroids, etc. in the universe. If they have above mentioned conditions (enough nutrients, suitable temperatures and other necessary environmental conditions for survival) for survival, they could survive. If they lacked enough nutrients required for survival or the temperature was too hot or too cold to be suitable for survival, they would not survive. That is to say that human, animals, flowers, trees, grasses and other plants could be located in different parts of the universe. Whether they could survive or for how long they could live completely relied on survival 
conditions they could get and whether their body structure and cells with atomic and molecular structures and components were consistent with the law of life survival. In addition to necessary survival conditions, when humans, animals, trees, grasses, flowers and other plants had normal reproductive abilities and other necessary conditions for reproduction, they would produce next generations. Some of them lasted until nowadays by reproduction of generations whereas others unfortunately failed to reproduce a new generation or reproduced one, two or more generations, but the latest generation died unexpectedly before reproduction or lost reproductive capability and hence did not keep reproduction of generations to last until now.

It is well-known that newborn babies are too young to get food independently or feed themselves. They acquire nutrients usually with their parents' or other people's help. When the earliest humans were born on the earth, how did they get nutrients for survival and growth? As the foregoing part mentioned, after black hole explosion, preparations for human and animal development and births started simultaneously and automatically. When the fertilized egg cell of human or animal in related development environment started differentiation and grew up into the fetus until human or animal was born, the time for this process is different. Actually, many animals before birth have shorter or much shorter period of time for their fetus formation, development and maturity than humans. When the earliest human was born, the earliest human baby must have been raised by a certain adult animal or animal family. That is to say that the animals including many mammalian animals were born on the earth or appeared in the world earlier than humans due to many mammalian animals' (e.g., wolf, leopard, dog and raccoon) shorter or much shorter embryo and fetus growth or gestation periods than humans in addition to many other animals. As a result, the earliest humans survived and grew with the animal's help. Research has shown that the average length of animal gestation time depends on the animal, e.g., wolf (63 days), raccoon (63 days), dog (63 days), leopard (95 days), lion (108 days), tiger (103 days), pig (114 days), goat (150 days) and sheep (150 days), shorter or even far shorter than human gestation period 274 days on average though some other animals, e.g., camel (410 days), donkey (365 days) have longer gestation periods than humans (Hill, 2021). Bettelheim (1959) noted that Ogburn believed that there was no sound evidence of human children raised by animals. However, people still heard true stories about contemporary human children raised by animals such as wolf, bear or leopard, etc. up to now. LaPointe (2005) noted that wolf-children meant that human children had been allegedly raised by animals, especially wolves and there were some records or reports, e.g., Lithuanian bear child in 1661, leopard child of India in 1920, sheep child of Ireland in 1672, Syrian gazelle child in 1946, pig boy of Holland in the 19th century, etc. Candland (1993) also noted that there was the earliest wolf-boy from Hesse in 1344, an Irish sheep-boy described in 1672, a Lithuanian bear-child observed to have been suckled by bears in 1661, and two girls named Kamala and Amala suggested to have been raised by wolves in northeastern India this century. It was reported that human children were raised by wolves in India (Bettelheim, 1959). Human babies raised by animals behaved more like an animal after they grew up (Bettelheim, 1959). These studies or reports indicated the case that human babies or children were raised by animals existed indeed. They also demonstrated that though people were told to be far away from those fierce animals (e.g., wolf, leopard, bear, etc.) for avoiding being harmed when they received education during childhood, several or multiple human children were raised by fierce and non-fierce animals even just in the past few centuries, which demonstrates the rarely seen or observed unusual behavior of animals related to humans and also provides a powerful link with the earliest human survival and growth.

When did humans leave animals that once helped them survive and grow and start to live independently? It is inferred that when human ancestors felt that their lives were threatened by fierce animal family members, animal partners, friends or/and neighbors especially when there were severe famines or the food which these fierce animals could seek to find was insufficient to satisfy their stomach needs, human ancestors felt secure no longer and started to escape from 
these animals. They attempted and finally found a secure place to live in. Nowadays, it is wellknown that people are generally afraid of directly staying together with fierce animals except animal keepers in the zoo. This case is obviously because fierce animals usually need a large amount of food daily and rarely can independently find so much food in places which humans live in, control and manage. As such, it is almost impossible without harming humans they directly meet except in general cases animal keepers in the zoo who take care of their food and are familiar to them. If the earliest human survival and growth were helped by non-fierce animals like sheep, etc., they left the animal family without being harmed by these animals. However, they must have been endangered by fierce animals nearby or coming from far-off places. As a result, they no longer felt secure and escaped from the place where they originally lived. Similarly, they tried and finally found a secure place and started to live independently. In any case, since humans left animals, they started to experience the process from crawling like animals to gradually standing up for more food, new tools, etc. for a more comfortable survival and growth.

\section{Difference in the Brain of Human, APe ANd Animal Started FROM THE ORIGIN OF THEIR RESPECTIVE LIFE}

As above-mentioned, at the birth of the universe, under gravitational force of the atomic magnetic field, adjacent atoms attracted mutually and formed atomic and molecular structures of the fertilized egg cell and related development environment of humans or animals. The fertilized egg cell in the related development environment differentiated, grew and formed different tissues and organs such as brain, heart, lung, etc. Among these tissues and organs, brain plays a crucial role in intelligence activity. Actually, humans are more intelligent than apes whereas humans and apes are more intelligent than monkeys (Roth and Dicke, 2005). What lead to the difference in human, ape and animal intelligence? The paper also attempts to find the root causes leading to the difference in the human, ape and animal intelligence and clarify why humans neither evolved from apes nor shared a common ancestor with apes from a physiological perspective. In general cases, normal adult human brain is characterized by brain neuron property and counts in specialized areas and brain structure which match the most complicated cognitive functions involved in most complicated language, strong analysis, reasoning and judgment, etc. Normal adult gorilla brain is characterized by brain neuron property and counts in specialized areas and brain structure which match enough less complicated cognitive functions involved in less complicated language, weaker analysis, reasoning and judgment, etc. compared with the normal adult human brain. Normal adult animal brain is typical of brain neuron property and counts in specialized areas and brain structure which match simpler cognitive functions involved in simpler language, weaker analysis, reasoning and judgment, etc. compared with the normal adult gorilla brain. In other words, intelligence difference in normal adult human, ape and animal brains can be explained based primarily on brain neuron property and counts in specialized language and thinking areas and brain structure though there is also difference related to intelligence from other related aspects of brain and of the whole body.

Research has shown that human neocortical pyramidal neurons are three times larger than rodent pyramidal neurons, which is associated with the three times larger and more complex dendrites in human pyramidal neurons than in mouse or macaque (Mohan et al., 2015, see Goriounova et al., 2018), but also human pyramidal neuron dendrites receive one time more synapses than rodent pyramidal neuron dendrites (DeFelipe et al., 2002, see Goriounova et al., 2018). Besides, MoraBermúdez et al. (2016) showed that humans and apes have striking resemblances in cytoarchitecture, cell type composition and neurogenic gene expression programs. About $99 \%$ of human genetic matter is shared with gorilla and chimpanzees (Dobrovolsky, 2009). However, Schörnig et al. (2021) noted that human cortical pyramidal neuron dendrites are longer and more 
branched than chimpanzee pyramidal neuron dendrites (Bianchi et al., 2013a) whereas pyramidal neuron synaptogenesis and development in humans and chimpanzees may be longer than in monkeys (Bianchi et al., 2013b). Thrombospondins are extracellular-matrix glycoproteins controlling synapse formation and neurite development, however, human cerebral cortex has approximately 6 times greater expression of thrombospondin 4 messenger RNA than the cerebral cortex of champanzees and macques (Cáceres et al., 2007), which indicated that more thrombospondins provided a basis for normal production of more synapses, and further demonstrated the physiological causes why cerebral cortex neuron synapses in humans were more than in apes and animals. Dendritic and spine number, size and morphology play one of crucial roles in integrating signals coming from individual synapses (Martínez-Cerdeño, 2016), which is closely correlated with cognitive ability. Neuron dendrites and dendritic spines significantly affect the connectivity of the brain and are responsible for long-term synaptic plasticity associated with memory and learning (Smrt and Zhao, 2010) or reasoning. Analysts learned to find solutions to complex tasks through mixed-initiative reasoning, integrated with previous knowledge, experience, etc. (Boicu et al., 2005), which indicates that learning requires reasoning in processing complex problems. The above studies also exhibited that neuron dendrites and dendritic spines are correlated with reasoning or thinking and memory. Other study also demonstrated that the integrated and functional roles of the neuron rely primarily on dendritic and synaptic structure, function and plasticity (Seong et al., 2015). The size of dendrites in these neurons is indeed positively associated with the whole cerebral cortex connectivity (Scholtens et al., 2014, van den Heuvel et al., 2015, see Goriounova et al., 2018), displaying that the larger dendrite in the neuron is closely correlated with the faster synaptic inputs (Testa-Silva et al., 2014) whereas synapse acts as a connection between two neurons (Babu, 2020). Larger neurons caused by larger dendrites can encode a larger number of rapidly changing temporal information more precisely in their output than smaller neurons caused by smaller dendrites (Goriounova et al., 2018). As a result, larger and more complex dendrites are closely linked with higher intelligence (Goriounova et al., 2018). Other research has also shown that pyramid neurons with dendrites and synapses are linked with higher cognitive functions (Goldman-Rakic, 1999, see Schörnig et al., 2021). Gemmell et al.'s (2012) study revealed that the volume or size of pyramidal neuron in hippocampal subfields CA1 and CA2 was 10\%-20\% smaller in those patients with delayed poststroke dementia or ischemic vascular dementia or mixed Alzheimer disease and vascular dementia syndrome or Alzheimer's disease compared with elderly groups with normal cognitive functions. This study indicated that neuronal dendrite size and complexity is significantly associated with normality of cognitive functions. However, Freeman et al (2008) made an examination of the cerebral cortex of 27 normal elderly people at the age of 56-103 and found that all these examined old people had normal cognitive functions and had no relatively reduced total neuronal numbers in frontal and temporal neocortex areas in spite of the relatively big age difference, but had obvious neuron shrinkage which signified the reduction of dendritic size and complexity. Actually, this study indicated that the reduction of dendritic size and complexity in a normal range did not negatively affect the normality of cognitive functions. Simultaneously, these studies also reflected the important role of the basic shape of brain neuronal dendrites in cognitive functions. Research has shown that abnormal or abnormally immature dendrite and synapse morphogenesis in human brain neurons can imply a variety of nerve developmental disorders (Seong et al., 2015), which indicated that abnormal or abnormally immature human brain neuron dendrites, synapses or property predicted the abnormalities of human cognitive ability and behavior. Studies on brain neurons of both humans and animals with autism and related neurodevelopmental diseases revealed the decreased size and number and altered morphology of dendrites and increased spine immature morphology (Martínez-Cerdeño, 2016), which indicated that the decrease of dendrite size and complexity and increase of immature structure of dendritic spine had exceeded the normal scope, which are correlated with autism, similarly displaying the importance of synapse morphology and size and mature synapse number in cognitive functions in addition to dendrite morphology, size and number. Research has 
shown that abnormal alterations of the dendritic spine structure and distribution were found in diseases such as various mental retardations, etc. due to failure in formation of normal spines causing cognitive and motor deficits (Smrt and Zhao, 2010), which further indicated the importance of dendritic spine number, size and morphology in cognitive activities. All these above studies also indicated that the difference of human, ape and animal in brain neuron property supported the difference in their respective brain functions involved in language, analysis and reasoning and judgment, etc.

In addition, humans have much more neurons in the cerebral cortex than apes and other animals. Herculano-Houzel et al. (2014) demonstrated the African elephant brain contains 257 billion neurons, about three times more than the human brain on average, but $97.5 \%$ of the elephant brain neurons are located in the cerebellum and only 5.6 billion neurons are located in the elephant cerebral cortex, which is about one third of human cerebral cortex neuron counts. It is noted that elephant cortical neuron number is 11 billions and chimpanzee cortical neuron number is 6.2 billions (Roth and Dicke, 2005, see Roth, 2012). In any case, human cortical neurons are 12-15 billions, indeed more than the cortical neurons of whales and dolphins and elephants with much larger brains and of apes and other animals (Roth, 2012). Actually, humans have much more neurons in specialized language and thinking areas than apes and animals. The great reduction of neurons in hippocampus and cortex is robustly correlated with dementia characterizing Alzheimer's disease symptom, but there is no significant difference between the elders with normal cognitive functions and asymptomatic patients with Alzheimer's disease (Andrade-Moraes et al., 2013), which indicated that normal neuron number in specialized language and thinking areas in the human brain plays an indispensable role in normal language cognition, memory, processing and thinking. Demented patients with Alzheimer's disease presented language and cognitive impairment such as inability to process the discourse as a whole, marked lexical and discourse deficits at the early and intermediate stages, which are involved in temporal neocortex concerning lexical retrieval (Caramelli et al., 1998), which similarly demonstrated that these demented patients experience difficulty in language communication, memory, processing and cognition and thinking. Grouios and Ypsilanti (2011) demonstrated that Down syndrome is characterized by chromosomal abnormality, language and cognitive impairments, abnormal neuromotor, early aging, etc. frequently correlated with Alzheimer's disease symptom, which also similarly indicated that people with Down syndrome have difficulty in language communication, memory, thinking, movement, etc. Indeed, research has revealed that children with Down syndrome from birth had $20-50 \%$ fewer neurons, lower neuronal density and distribution particularly in cortical layers II and IV (Wisniewski, 1990), which also similarly indicated that lower than normal neuron number in certain areas of the cortex could hamper the normal work of human language and cognitive and neuromotor functions and further demonstrated that sufficient cortex neuron number in specialized language and thinking areas is indispensable for normal human language communication, memory, cognition and thinking. These studies also indicated that since humans have stronger language and thinking abilities than apes and animals, humans must have more neurons in specialized language and thinking areas than apes and animals. Premack (2007) noted that compared with apes, humans have many more slender tapered neurons (labeled VENs) situated in the frontoinsular cortex and the anterior cingulate cortex involved in emotional cognition, which was rediscovered by Hof and associates in 1999 through microscope. Their research result indicated that humans have much more brain neurons in emotional cognitive areas than apes. Functional Magnetic Resonance Imaging have revealed that memory and reasoning activities were demonstrated in certain areas of cerebral cortex (Ruff et al., 2003). Certain areas of cerebral cortex are indeed closely associated with language such as lexical and semantic retrieval, semantic integration, as well as memory and reasoning, etc. (Bunge et al., 2005). Prefrontal cortex is correlated with reasoning and solving problems (Bunge et al., 2005, see also Ruff et al., 2003). The Parietal cortex neurons are linked with the possible quantity addition and subtraction 
activities supporting task decision-making (Yang and Shadlen, 2007). These studies indicated the crucial role of some areas of cerebral cortex in intelligence activities such as language and thinking, etc.

Premack (2007) showed that human minicolumns with 80-100 neuros bundled vertically located in the left planum temporale supported language and perhaps music, but were organized differently than those of chimpanzees and rhesus monkeys. The author also recorded that human minicolumns were $51 \mu \mathrm{m}$ on average, much wider than those of the chimpanzees and monkeys in $36 \mu \mathrm{m}$. This study also revealed that humans have the brain structure distinguished from the brain structure of apes and animals and corresponding neurons specializing in language and perhaps music to support much more complicated human language and perhaps music skills than apes and animals. The whole human prefrontal cortex neurons in layer III are significantly more widely spaced than those in great apes (Teffer and Semendeferi, 2012), which further indicated the difference in the brain structure of humans and apes. In fact, research had found that early human brain was organized differently from ape brain (Holloway et al., 2009). Passingham (2009) noted that humans and macaque monkeys showed a difference in the proportions of different regions and microstructures of their brains. He also noted that "The prefrontal cortex, defined as the granular frontal cortex forms $28.5 \%$ of the neocortex in the human brain but only $11.3 \%$ in the macaque brain."; "When related to the brain as a whole, the frontal polar cortex, area 10 is proportionately twice as large in the human brain as in that of the chimpanzee." (p. 2). These studies suggested that there was a difference in the brain structure of humans, apes and animals, which match their different number and property of specialized neuron involved in language, analysis, reasoning, judgment, etc.

Many studies have displayed the difference among humans and apes and other animals in cognitive capability and behavior. After taught by humans, animals could connect artificial labels with objects or properties of objects, indicating animals could learn words and corresponding meanings (Cheney and Seyfarth, 2010). Meijer's (2021) observation demonstrated that the gray parrot Alex knew over 100 words. Larger-brained dolphins and smaller-brained sea lions could understand novel and unique gesturally conveyed messages under human instruction (Schusterman and Gisiner, 1988). However, animal communication seems to be limited to message conveyance and is constrained to a different extent (severe extent, e.g. bees, less severe, e.g., parrot) based on different animals (Dobrovolsky, 2009). Human cortex information processing capabilities are stronger compared with animals, even those large-brained mammals such as elephants, dolphins and whales (Roth, 2012). Systematic investigations have recorded that the great apes can learn, comprehend and use symbols to exchange information and use relatively simple rules to organize these symbols (Rumbaugh et al., 2009). Other research has showed that gorillas Koko could understand around 1000-word sign language and around 2000 spoken English words taught by humans, which signified that she could express her own ideas in sign language, and gorilla Michael learned about 600-word sign language at a similar pace (The Gorilla Foundation, 2018). It noted that other apes also have similar capabilities of learning and acquiring a sign language at this level in other ape studies (see also Rumbaugh and SavageRumbaugh, 2001). However, little evidence showed that apes could combine words taught by humans into a sentence like phrases (Cheney and Seyfarth, 2010). Though sign language invented and learned by apes is much more complicated than one, two or a few words spoken language invented and learned by apes, their sign language is still much simpler than human sign language. Bonvillian and Patterson's (1997) investigation on gorilla Koko and young deaf children at similar ages showed that these children learned sign language and gestures more rapidly than the gorilla and the gorilla's vocabulary size and her sign language complexity were relatively limited and could not keep up with those of children especially over time. In fact, human language is more productive and more flexible in controlling and using these symbols than any of known ape and all other animal communication systems (Dobrovolsky, 2009). Brinck and Gärdenfors (2001) 
demonstrated that humans have higher attentional complexities to become more cooperative and have more ways to achieve a goal than apes, indicating that higher cognitive ability of humans than apes promoted their higher cognitive behaviors. Whiten (2013) noted that apes have stronger imitative abilities (e.g., gestures) than monkeys, e.g., apes could imitate how to crack a walnut and other nuts using a stone hammer whereas monkeys failed, which demonstrated that higher cognitive ability of apes than animals like monkeys worked in a way matching their higher cognitive behavior. Indeed, humans are more intelligent than great apes, which are more intelligent than monkeys and other animals (Roth and Dicke, 2005). These studies also demonstrated the difference in cognitive capability and behavior among humans and apes and animals, which match with their respective property and counts of brain neuron in specialized language and thinking areas and corresponding brain structure.

It is not excluded that a very small number of animals show the property and count of more brain neurons more beneficial to specialized language and thinking accompanied with corresponding brain structures compared with the vast majority of animals of the same genre. However, generally speaking, birds of a feather flock together. When very few animals with unusually cleverer brains grew together with their genre of population with normal animal brains, unusual advantages of their brains could not be constantly developed or inherited through generation after another. In other words, it is unrealistic that they passed on their intellectual characteristics to their offspring of generation after generation since such animals are rare or in a very small number. As far as humans are concerned, if some people congenitally partly or even almost did not have property or enough number of normal human brain neuron in specialized language and thinking areas for normal thinking and language learning, they could not belong to normal human groups. For example, a baby was born mentally disabled, which signified that when he/she was old enough to go to school or even grew up into adulthood, he/she could not learn how to speak or understand what other people said like a mentally normal child or adult. Some of such babies cannot live until adulthood due to multiple abnormal health problems; after growing up into adulthood, generally some others had fewer or no offspring. As a result, such human intellectual heritability stopped or gradually decreased. Anencephaly is a neural tube birth defect which causes lack of a major portion of the brain, and infants with anencephaly die before birth or within a few hours or days of birth (Diniz, D. (2007, see Ballantyne et al., 2009, see also Ryskamp, 2010), rarely live past one year, only one recorded female infant lived until the age of four (Foreman, 1999, see Ryskamp, 2010), which display that persons with so severe brain defects have a very short lifespan and cannot live until adulthood to have offspring. Such infants are generally also accompanied with other abnormal health problems such as the absence of the neck and of cranial vault, bulging of eyes, abnormal spine (spinal cord absence or dysplasia), etc. (Korpova et al., 2012). Children born with Down syndrome displaying language and cognitive and other related health impairments can live to about 47 years old on average in 2007 whereas in 1960 such children can live only to about 10 years old on average (CDC, 2020), which exhibit an obvious increase of survival rates during approximately 50 years. Other research also demonstrated that people with Down syndrome generally die 28 years earlier than the general population (O'Leary et al., 2018). However, in any case, research has demonstrated that women and girls with birth defects had reduced survival rates and less possibility of having a child compared with those women and girls without birth defects in Norway (Skjaerven et al., 1999). Similarly, research has also shown that males with registered birth defects in Norway have higher mortality rates and survivors have less possibility of having a child compared with those males without birth defects (Lie et al., 2001). The registered birth defects in Norway included an estimated $60 \%$ of Down syndrome and an estimated $80 \%$ of cleft lip cases, anencephaly, spina bifida, etc. (Lie et al., 1994, see Lie et al., 2001). These studies indicated that though there are still mentally disabled persons in the world, such population is in a very small number compared with the vast majority of cognitively normal population. In fact, it has been extensively accepted that learning and speaking a complicated language is one of remarkable characteristics of humans 
distinguished from animals from the ancient time to present. Therefore, during billions of years of human evolution, those people who could not learn to speak a human language were gradually reduced. Nowadays, cognitively normal people we see have the ability to learn to speak at least one human language. As such, present cognitively normal humans on the earth generally have no big difference in intelligence, but have an essential difference in intelligence from the gorilla and animal.

During billions of years of physical and mental evolution, the brains of humans, apes and animals became cleverer, but humans, apes and animals have an essential difference in the earliest brain structure formed and the number and property of earliest brain neuron in specialized areas involving in language, analysis and reasoning and judgment. That is to say that human did not evolve from apes. Human became humans, which were decided by the human brain structure and the property and number of brain neuron in specialized language and thinking areas formed at the birth of the universe. Such brain structures and minimum counts and property of brain neuron in specialized language and thinking areas for becoming a human decided that humans could gradually grow to invent and learn new things (e.g., complicated and abstract languages, complicated tools) whereas the brain structures of ape and animal and the numbers and properties of their brain neuron in specialized language and thinking areas decided that they could speak only one or two or a few words language each time invented or learned by themselves and use simple tools.

Though humans and animals became cleverer during billions of years of evolution, the total trend of intellectual development progressed very slowly and intellectual evolution of family generations was subtly up and down like a tiny wave, but on the whole gradually went like an upward spiral. Actually human intellectual development is complicated, depended primarily on heredity and external stimulations and nutrients. Killeen (2004) noted that individual traits such as physical appearance, personality, intellect, etc. are affected by heredity, environmental factors and nutrients (e.g., whether to eat high-fat diets and smoke), indicating that human mental and physical characteristics is closely associated with heredity, external factors including environmental stimulation, etc. and nutrient factors including selected food nutrient quality, quantity and variety, etc. Shakeshaft et al.'s (2015) study also demonstrated that high intelligence is determined by genetic and environmental factors related to intellectual development. It is wellknown to plant and harvest melons and plant and harvest beans, which is described as the genetic law of living things. It indicated that living things pass on traits to their offspring. Human as one of living things, its genetic law is no exception. That is to say human parents can also pass on their mental and physical characteristics to their children. The hereditary characteristic of intelligence is determined by a large number of genes of very small effect (Plomin and Deary, 2014, see Shakeshaft et al., 2015). Savage et al.'s (2018, p. 912) genome-wide study of 269867 individuals revealed that "Associated genes are strongly expressed in the brain, specifically in striatal medium spiny neurons and hippocampal pyramidal neurons.", indicating strong genetic correlation with brain neurons linked with intelligence. Trzaskowski et al.'s (2014) survey on DNA (Deoxyribonucleic acid with genetic codes) of 3000 unrelated children aged between 7 and 12 showed that genetic influence is closely correlated with children's intellectual quotient. Marioni et al.'s (2014) research on DNA-derived heritability of 6815 unrelated Generation Scotland participants at median age 57 years demonstrated that heritability of intelligence partly impacted cognitive ability associated with education and was compatible with other researchers' results: education extent was primarily environmentally or genetically driven. If father and mother have similar intellectual levels, children could be cleverer than their parents if the intellectual heredity from their parents had good variation or children received more external stimulations than their parents (e.g., sufficiently more education, much more complicated social communications and individual experiences). Research has shown that limited but converging evidence displayed that process-based complex working memory training have a positive impact 
on academic capabilities (Titz and Karbach, 2014), which indicated the beneficial role of external stimuli like training or education in improvement of cognitive and academic ability. Human babies were raised by non-human parents or socially and physically isolated when they grew up. They could neither speak a human language nor behave as well as a normal human, but more like an animal after they grew up (Bettelheim, 1959), indicating that their cognitive abilities in language and behavior did not develop as a normal human. When they were raised by animals or socially and physically isolated when growing up, their advanced potential of human intelligence or cognitive ability were not developed as being normally raised by human with age, which demonstrated the significant impact of human external stimulations like complicated social communications and rich experiences on brain development in addition to the minimum number and property of normal human brain neuron in specialized language and thinking areas and corresponding brain structures and other related factors for being able to speak a human language.

Some children have intellectual levels similar to those of their parents if they had development experiences similar to those of their parents and the intellectual heredity from their parents had no detectable variation and others are less clever than their parents if the intellectual heredity from their parents had bad mutations or they have received sufficiently fewer external stimulations than their parents (e.g., sufficiently less education due to the war, sufficiently less and simpler social communications and individual experiences). Plomin and Von Stumm (2018) recorded that recent research revealed that difference in $20 \%$ of heritability of intelligence is due to inherited genome sequence differences, indicating that heritability of intelligence has good or bad genetic variants. Arslan and Penke (2015) noted that intelligence disability is caused mainly by new mutation, which was regarded as a bad variant. If father and mother have some or bigger difference in intelligence, children maybe inherited their cleverer father's or mother's intelligence or less clever mother's or father's intelligence or almost half of their father's and mother's intelligence each, etc. As such, children are as clever as their father or mother or as less clever as their father or mother or between their parents' intellects, etc. if there were no detectable mutations in intellectual heritability and they had developmental experiences similar to those of their parents. That is to say that an intelligent man or woman does not ensure that they would have a more intelligent child than he or she. With the progress of human society and constant technological innovations, in most cases new generations often had more external stimulations (e.g., more extensive information reading and knowledge learning and better food nutrients to develop their brain than their parents), but some exceptional cases also happened. For example, children during the war had fewer opportunities to learn new knowledge, obtain extensive information and good food nutrients, etc. to develop their brain than their parents who never experienced a war or experienced a war over a much shorter time. Since there were written records several thousands of years ago, it is well-known that wars had used to happen, far more frequently than nowadays, which hampered affected children from developing their brains better. Kesternich et al.'s (2012) study noted that World War Two caused severe famines in some regions, which resulted in the cognitive and mental problems of individuals including children and adults as shown by Neugebauer et al. (1999) and Rooij et al. (2010). Lack of proteins cadherins and catenins can lead to abnormal dendrite and synapse morphogenesis, which predicted various disorders of nerve development (Seong et al., 2015) closely associated with cognitive and mental problems. Besides, when children were very young, if both or either of parents were seriously ill or lost employment over a long period of time and the family had no other financial sources or aids which are enough to support their lives, their children's healthy diets would be negatively affected, which were also similarly disadvantageous to their children's brain development.

Moreover, more than 2000 years ago, some of books and articles and poems, etc. of China's and many other countries' scholars extensively read by generation after another in various fields 
showed high intelligence and wisdom. For example, Aldrete (2011, p. 2) recorded that between $500 \mathrm{BC}$ and $600 \mathrm{BC}$, new thinkers around the world occurred and wrote new philosophies and religions, e.g., "Confucianism and Daoism in China, pre-Socratic philosophy in Greece, Buddhism and Jainism in India, and Zoroastrianism in Persia", which still have a significant influence on present day related countries. Han and Qiao (2009) noted that the book "Wujing Tongyi" recorded the mechanism of solar eclipses to improve the ancient calendar around 2000 years ago and provided valuable contributions to research on present day related fields (e.g., astrophysics concerning the rotation rate of the earth). Numerous poems were created, e.g., The

Tale of the Shipwrecked Sailor 2040-1782 BC (Mark, 2012), the Vedas around 1500 BC (Mark, 2020), Shijin (The Book of Poetry) 1100 BC - 600 BC (Chen et al, 2008) and Homer's epic poems "Iliad" 800 BC and "Odyssey" around 800-600 BC (Finkelberg, 2011, see also Aldrete, 2011). Invention of written language based on written records kept around $3500 \mathrm{BC}$ (Wei, 2012) was not easy, evidently requiring high intelligence. Around $2500 \mathrm{BC}$ use of boat was discovered (Dixit, Hazarika and Davim, 2017). Invention of boat enabled people to easily travel on water for visiting far-off places, meeting new people, exchanging goods and ideas with more people, live a life on water and find more food in sea, rivers and lakes, etc. About 2000 years ago, many other deeply impressive inventions also showed high creativity. For example, inventions of oil pressing device, water-driven grinder for food processing, weaving technology, paddle blade machines for continuous water drawing, crossbows, diverse manufactured metal products (Hsiao and Yan, 2014) and paper making and compass and three-mast ship and primitive steam engine and windmills for producing motive sources, e.g., generating electricity, milling grains, lifting water from wells, sawing wood, etc. (Dixit, Hazarika and Davim, 2017) further provided convenience and comfort for human life (e.g., travelling at sea and on land, agricultural work, everyday life, keeping records, hunting animals and against invasion). Around simultaneously the construction of the Step Pyramid also showed quite astonishing achievements (Aldrete, 2011).

Undoubtedly, all these astonishing achievements achieved at least 2000 years ago years required creative ideas and high cognitive abilities. Inventions of all types of tools and technologies and oral and written languages in ancient times have left deep traces for development of modern civilization. That is to say that in the past several thousand years, on the whole human intellect had no obvious change. As such, it is referred that during past billions of years, globally human intellectual development must be gradual and very slow. Research demonstrated that 2-4 million years ago fossil hominid brain sizes varied from around 385 to $1700 \mathrm{ml}$ whereas modern human brain size is around $1400 \mathrm{ml}$ on average (Holloway et al., 2009), indicating that there was no remarkable change in human brain size during the past 2-4 million years and different persons have similar or different brain sizes. That is also to say that human intellectual development depended primarily on heredity and external stimulations and good nutrients, which did not result in a radical or essential change in intellectual increase on the whole and further indicated that the formation of complicated molecular structures and an enough large number of brain neuron in specialized language and thinking areas billions of years ago played a crucial role in difference of human brain from ape and animal brains because the big difference in the number and property of brain neuron in specialized language and thinking areas and brain structure among humans and apes and animals decided that humans could find and generate much more external stimulations and seek and produce much better nutrients and invent and use much more complicated languages and tools than apes and animals except common natural external stimulations (e.g., complicated mountainous and hilly areas).

\section{Human Skin Color AND Sunlight ShINNING}

Since humans can fall on and inside the earth or other planets, etc. at the beginning of the universe as the foregoing mentioned, why don't we now see native people in the same place have 
no different skin colors except some migrants and their descendants? It is observed that human skin colors seem to be closely correlated with sunlight. That is to say that due to difference in the amount of the sunlight shining over their bodies, it is seen that human skin color gradually varies from white in Europe to light brown and brown in North Africa to black in Central and Southern Africa, also from North Pole with the least sunlight to North Africa with mild sunlight and then to the vicinity of the equator with the most sunlight. Similarly, human skin color also varies from light yellow in the northeast of China to brown or dark brown in India, also gradually from North with less sunlight to South with the more sunlight in Asia. Though Western Europe and the northeast of China are in the similar latitude, Western European skin color is white while the skin color of the northeasterner of China is light yellowish. That indicated that Western Europeans have a lighter skin color than the northeasterners of China, which is also closely associated with the amounts of the sunlight shining over them. Western Europe with the oceanic climate has sufficiently less sunlight compared with the northeast of China with the monsoon climate. That further demonstrated that human skin color is closely associated with the amounts of sunlight shining over their skin. In addition, human skin color is also closely correlated with the heredity mainly from or between their parents' skin colors. Prud'homme-Généreux (2011) showed that parents' genetic components including skin color, etc. will be disproportionally passed on to their offspring. As a result, difference in human skin color is decided primarily by the total amount of sunlight shining on the skin of generations after family generations except for possible genetic mutation.

An inference is made that if humans with white or yellow skin are persistently shone by the sunlight as in Africa, their skins would gradually become dark or even black in millions or billions of years. However, with the development of industrial revolution in the past few centuries and the gradual spread of agricultural mechanization, people who live in Africa where there is the largest amount of sunlight are rarely exposed to as much sunlight as people there used to. People stay indoors and are shielded from the Sun in most of time. As a result, if people with white or yellow skin migrate and live there, in millions or billions of years their skin colors should have no obvious change or get a little darker than before at most, nevertheless, depending on individual amounts exposed to sunlight. African black people's skin color should become some lighter (e.g., light black, even brown) after a long time (e.g., millions or billions of years) if they stay outdoors and are not exposed to the Sun in most of time. Similarly, the skin color of descendants of people with black or yellow skin who migrated to Europe would also get lighter than before after a long time (e.g., millions or billions of years).

It is also inferred that change of skin color caused by change of amounts of sunlight shining over immigrants' descendants should link mutations of skin color genes after numerous generations. If ancestors migrated to places with sunlight shining less or much less than those places where they lived before migration, the skin color of the descendants after their numerous generations would change more particularly when migration ancestor used to work under the Sun e.g., in the farmland. Besides, it was also possible that billions of years ago when humans were born, humans carried different skin color genes, which presents different skin colors. Millions or billions of years, similarly migration descendant's skin color varied to different extents, depending also primarily on the amounts of sunlight which their numerous older generations once received. As a result, we see that native people in the same place have the same or similar skin color except some immigrants and their descendants. In either case, research is also expected to confirm that change of skin color gene(s) should be able to lead to immediate change of the skin color. 


\section{SUMMARY AND CONCLUSIONS}

With black hole explosion under incredibly high temperatures leading to cosmic information billions of years ago, all matters had been in gaseous phase. With temperature dropping, adjacent atoms which made up gases attracted each other and formed a variety of big, small or tiny gaseous lumps. Under atomic attractive forces, adjacent gaseous lumps attracted mutually and connected and fused with one another into a bigger gaseous lump. With the temperature persistently dropping, the gaseous lump became colder and contracted and got smaller according to the principle of expanding when heated and contracting when cooled in general cases. Gradually it developed and formed a human- or animal- like embryo and fetus or a plant-like embryo and seed. If it had the same compositions as a human, cow or sunflower, the human, the cow or the sunflower formed. Similar cases happened to other humans, animals and plants. Due to their much shorter gestation periods than humans, many mammalian animals (e.g., wolf, leopard, dog and raccoon) came to the world or were born on the earth much earlier than humans. As a result, the earliest humans survived and grew with the adult animal's help. That is to say that the earliest non-life forms of all life were born together with stars, planets, etc. Or preparations for human and animal and plant development and birth started simultaneously and automatically at the early period of the universe. Humans neither evolved from apes nor shared a common ancestor with apes.

\section{ACKNOWLEDGEMENTS}

I would very much like to thank anonymous supporters for their strong scientific spirit and great kindness and also for providing Bibliography for me reading online free of charge. Without their persistent support, the completion of the paper would be impossible. Many thanks!

\section{REFERENCES}

[1] Aldrete, G. S. (2011). History of the Ancient World: A Global Perspective. Virginia: The Great Courses.

[2] Andrade-Moraes, C. H., Oliveira-Pinto, A. V., Castro-Fonseca, E., da Silva, C. G., Guimarães, D. M., Szczupak, D., Parente-Bruno, D. R., Carvalho, L. R. B., Polichiso, L., Gomes, B. V., Oliveira, L. M., Rodriguez, R. D., Leite, R. E. P., Ferretti-Rebustini, R. E. L., Jacob-Filho, W., Pasqualucci, C. A., Grinberg, L. T. and Lent, R. (2013). Cell Number Changes in Alzheimer's Disease Relate to Dementia, Not to Plaques and Tangles. Brain, 136, 3738-3752.

[3] Arslan, R. C. and Penke, L. (2015). Zeroing in on the Genetics of Intelligence. Journal of. Intelligence, 3, 41-45; doi:10.3390/jintelligence3020041

[4] Babu, K. (2020) Sticking and Signalling at the Synapse. Resonance, 25, 419-429. https://doi.org/10.1007/s12045-020-0954-6

[5] Ballantyne, A., Newson, A. J., Luna, F. and Ashcroft, R. (2009) Prenatal Diagnosis and Abortion for Congenital Abnormalities: Is It Ethical to Provide One without the Other? American Journal of Bioethics, 9(8): 48-56

[6] Bettelheim, B. (1959). Feral Children and Autistic Children. American Journal of Sociology, Vol. 64, No. 5,455

[7] Bianchi, S., Stimpson, C. D., Bauernfeind, A. L., Schapiro, S. J., Baze, W. B., McArthur, M. J., Bronson, E., Hopkins, W. D., Semendeferi, K., Jacobs, B., Hof, P. R., Sherwood, C. C. (2013a) Dendritic Morphology of Pyramidal Neurons in the Chimpanzee Neocortex: Regional Specializations and Comparison to Humans. Cerebral Cortex, 23:2429-2436. https://doi.org/10.1093/cercor/bhs239

[8] Bianchi, S., Stimpson, C. D., Duka, T., Larsen, M. D., Janssen, W. G., Collins, Z., Bauernfeind, A. L., Schapiro, S. J., Baze, W. B., McArthur, M. J., Hopkins, W. D., Wildman, D. E., Lipovich, L., Kuzawa, C. W., Jacobs, B., Hof, P. R. and Sherwood, C. C. (2013b) Synaptogenesis and Development of Pyramidal Neuron Dendritic Morphology in the Chimpanzee Neocortex Resembles Humans. PNAS, 110, Suppl 2:10395-10401. https://doi.org/10.1073/pnas.1301224110 
[9] Blehl, M. F. (2006). Electric and Magnetic Power Paperback. USA: Pearson Scott Foresman.

[10] Boicu, M., Tecuci, G., Ayers, C., Marcu, D., Boicu, C., Barbulescu, M., Stanescu, B., Wagner, W., Le, V., Apostolova, D. and Ciubotariu, A. (2005) A Learning and Reasoning System for Intelligence Analysis. In Proceedings of the Twentieth National Conference on Artificial Intelligence, AAAI-05, Pittsburgh, Pennsylvania, USA, July 9-13, 2005

[11] Bonvillian, J. D. and Patterson, F. G. P. (1997). Sign Language Acquisition and the Development of Meaning in a Lowland Gorilla. In: C. Mandell and A. McCabe (Editors) The Problem of Meaning: Behavioral and Cognitive Perspectives, pp. 181-219, Elsevier Science B. V.

[12] Brinck, I. and Gärdenfors, P. (2001). Co-operation and Communication in Apes and Humans. Lund University Cognitive Studies, 88, ISSN 11018453.

[13] Brunken, J., de Wet, J. M. J. and Harlan, J. R. (1977). The Morphology and Domestication of Pearl Millet. Economic Botany, Vol. 31, No. 2, 163-174.

[14] Bunge, S. A., Wendelken, C., Badre, D. and Wagner, A. D. (2005) Analogical Reasoning and Prefrontal Cortex: Evidence for Separable Retrieval and Integration Mechanisms. Cerebral Cortex, Vol. 15, No. 3, 239-249 https://doi.org/10.1093/cercor/bhh126

[15] Cáceres, M., Suwyn, C., Maddox, M., Thomas, J. W., Preuss, T. M. (2007) Increased Cortical Expression of Two Synaptogenic Thrombospondins in Human Brain Evolution. Cereb Cortex, 17(10):2312-2321. doi: 10.1093/cercor/bhl140

[16] CDC (Centers for Disease Control and Prevention) (2020) Data and Statistics on Down Syndrome. Available from: https://www.cdc.gov/ncbddd/birthdefects/downsyndrome/data.html

[17] Candland, D. K. (1993). Feral Children and Clever Animals: Reflections on Human Nature. New York: Oxford University Press.

[18] Caramelli, P., Mansur, L. L. and Nitrini, R. (1998) Chapter 32 - Language and Communication Disorders in Dementia of the Alzheimer Type. In: B. Stemmer and H. A. Whitaker (eds.) Handbook of Neurolinguistics, pp. 463-473. Elsevier Inc: Academic Press

[19] Chen, J. Y. and Jiang, J. Y. (Translator, Modern Chinese), Wang, R. P. (Translator, English) (2008) The Book of Poetry (Chinese-English), 2 Volumes, 727 pages. Changsha: Hunan People's Publishing House.

[20] Cheney, D. L.and Seyfarth, R. M. (2010). Why Animals Don't Have Language? (The Tanner Lectures on Human Values at Cambridge University March 10-12, 1997).

[21] Christensen, K. R. (2001). The Co-evolution of Language and the Brain: A Review of Two Contrastive Views (Pinker \& Deacon). Grazer Linguistische Studien, 55, 1-20.

[22] DeFelipe, J., Alonso-Nanclares, L. and Arellano, J. I. (2002) Microstructure of the Neocortex: Comparative Aspects. Journal of Neurocytology, 31: 299-316. https://doi.org/10.1023/A:1024130211265

[23] Diniz, D. (2007). Selective Abortion in Brazil: The Anencephaly Case. Developing World Bioethics, 7(2), 64-67.

[24] Dixit, U.S., Hazarika, M. and Davim, J. P. (2017). A Brief History of Mechanical Engineering. Springer International Publishing Switzerland.

[25] Dobrovolsky, M. (2009) Chapter 16 Animal Communication. Pearson Education Canada

[26] Dorfmann, L. and Ogden, R. W. (2014). Nonlinear Theory of Electroelastic and Magnetoelastic Interactions. Springer Science + Business Media New York.

[27] Finkelberg, M. (ed.) (2011) The Homer Encyclopedia, Vol. III, 706-954. Blackwell Publishing Ltd.

[28] Foreman, M. W. (1999). Christianity \& Bioethics: Confronting Clinical Issues. Joplin, Missouri: College Press Publishing Co.

[29] Freeman, S. H., Kandel, R, Cruz, L., Rozkalne, A., Newell, K., Frosch, M. P., Hedley-Whyte, E. T., Locascio, J. J., Lipsitz, L. A. and Hyman, B. T. (2008) Preservation of Neuronal Number Despite Age-related Cortical Brain Atrophy in Elderly Subjects without Alzheimer Disease. Journal of Neuropathology Experimental Neurology, 67: 1205- 1212.

[30] Gemmell, E., Bosomworth, H., Allan, L., Hall, R., Khundakar, A., Oakley, A. E., Deramecourt, V., Polvikoski, T. M., O'Brien, J. T. and Kalaria, R. N. (2012) Hippocampal Neuronal Atrophy and Cognitive Function in Delayed Poststroke and Aging-Related Dementias. Stroke, Vol. 43, No. 3, 808-814 https://doi.org/10.1161/STROKEAHA.111.636498

[31] Goldman-Rakic, P. S. (1999) The "Psychic" Neuron of the Cerebral Cortex. Annals of the New York Academy of Sciences, 868: 13-26. https://doi.org/10.1111/j.1749-6632.1999.tb11270.x

[32] Goriounova, N. A., Heyer, D. B., Wilbers, R., Verhoog, M. B., Giugliano, M., Verbist, C., Obermayer, J., Kerkhofs, A., Smeding, H., Verberne, M., Idema, S., Baayen, J. C., Pieneman, A. 
W., de Kock, C. P. J., Klein, M. and Mansvelder, H. D. (2018) Large and fast human pyramidal neurons associate with intelligence. eLife, 7:e41714 DOI: 10.7554/eLife.41714

[33] Grouios, G. and Ypsilanti, A. (August 29th 2011). Language and Visuospatial Abilities in Down Syndrome Phenotype: A Cognitive Neuroscience Perspective. In: S. Dey (ed.) Genetics and Etiology of Down Syndrome, IntechOpen, DOI: 10.5772/20483.

[34] Hale, P. J. (2012). Darwin's Other Bulldog: Charles Kingsley and the Popularisation of Evolution in Victorian England. Science and Education, 21, 977-1013.

[35] Han, Y. B. and Qiao, Q. Y. (2009). Records of Solar Eclipse Observations in Ancient China. Science in China Series G: Physics, Mechanics and Astronomy, Vol. 52, No. 11, 1639-1645.

[36] Hawking, S. W. (1974). Black hole explosions? Nature Volume 248, pages 30-31.

[37] Herculano-Houzel, S., Avelino-de-Souza, K., Neves, K., Porfírio, J., Messeder, D., Mattos Feijó, L., Maldonado, J. and Manger, P. R. (2014) The Elephant Brain in Numbers. Frontier in Neuroanatomy, 8:46. doi: 10.3389/fnana.2014.00046

[38] Hill, M. A. (2021, Jan. 11) Embryology K12 Animal Development Times. Retrieved from https://embryology.med.unsw.edu.au/embryology/index.php/K12_Animal_Development_Times

[39] Holloway R. L., Sherwood C. C., Hof P. R. and Rilling J. K. (2009) Evolution of the Brain in Humans - Paleoneurology. In: Binder M.D., Hirokawa N., Windhorst U. (eds) Encyclopedia of Neuroscience. Springer, Berlin, Heidelberg, 1326-1338.

[40] Hsiao, K. H. and Yan, H. S. (2014). Mechanisms in Ancient Chinese Books with Illustrations. History of Mechanism and Machine Science 23. Springer International Publishing Switzerland.

[41] Johnson, R. (2001). Biology (6th edition). New York: McGraw-Hill Science/Engineering/Math.

[42] Kesternich, I., Siflinger, B., Smith, J. P. and Winter, J. K. (2012). The Effects of World War II on Economic and Health Outcomes across Europe, IZA DP No. 6296

[43] Killeen, A. (2004). Principles of Molecular Pathology. Totowa, NJ: Humana Press.

[44] Korpova, M., Miklosova, M., Dankovcik, R., Dudas, M. and Sivrev, D. (2012) Etiopathogenetic Similarities and Differences in Neural Tube Deffects. Trakia Journal of Sciences, Vol. 10, Suppl. 2, 262-266

[45] LaPointe, L. L. (2005). Feral Children. Journal of Medical Speech-Language Pathology, 13(1), VIIIX.

[46] Lie, R. T., Heuch, I. and Irgens, L. M. (1994) Maximum Likelihood Estimation of the Proportion of Congenital Malformations Using Double Registration Systems. Biometrics, 50, 433-444

[47] Lie, R. T., Wilcox, A. J. and Skjaerven, R. (2001) Survival and Reproduction among Males with Birth Defects and Risk of Recurrence in Their Children. JAMA, 285(6):755-60. doi: 10.1001/jama.285.6.755.

[48] Li, Z., Shen, J., Wu, W. K. K., Wang, X., Liang, J., Qiu, G. X. and Liu, J. M. (2012). Vitamin A Deficiency Induces Congenital Spinal Deformities in Rats. PLOS ONE, Vol. 7, No. 10, e46565.

[49] Marioni, R. E., Davies, G., Hayward, C., Liewald, D., Kerr, S. M., Campbell, A., Luciano, M., Smith, B. H., Padmanabhan, S., Hocking, L. J., Hastie, N. D., Wright, A. F., Porteous, D. J., Visscher, P. M. and Deary, I. J. (2014). Molecular genetic contributions to socioeconomic status and intelligence. Intelligence, Vol. 44, 26-32.

[50] Mark, J. J. (2012) The Tale of the Shipwrecked Sailor: An Egyptian Epic. World History Encyclopedia.

[51] Mark, J. J. (2020) The Vedas. World History Encyclopedia.

[52] Martínez-Cerdeño, V. (2016) Dendrite and Spine Modifications in Autism and Related Neurodevelopmental Disorders in Patients and Animal Models. Developmental Neurobiology, Vol. 77, No. 4, 393-404 https://doi.org/10.1002/dneu.22417

[53] Meijer, E. (2021) Animal Languages. Cambridge: The MIT Press.

[54] Mohan,H., Verhoog, M. B., Doreswamy, K. K., Eyal, G., Aardse, R., Lodder, B. N., Goriounova, N. A., Asamoah, B., Brakspear, A. B. B., Groot, C., van der Sluis, S., Testa-Silva, G., Obermayer, J., Boudewijns, Z. S., Narayanan, R. T., Baayen, J. C., Segev, I., Mansvelder, H. D. and de Kock, C. P. (2015) Dendritic and Axonal Architecture of Individual Pyramidal Neurons across Layers of Adult Human Neocortex. Cerebral Cortex, 25: 4839-4853. https://doi.org/10.1093/cercor/bhv188

[55] Mora-Bermúdez, F., Badsha, F., Kanton, S., Gray Camp, J., Vernot, B., Köhler, K., Voigt, B., Okita, K., Maricic, T., He, Z. S., Lachmann, R., Pääbo, S., Treutlein, B. and Huttner, W. B. (2016). Differences and similarities between human and chimpanzee neural progenitors during cerebral cortex development. eLife, 5, e18683. DOI: 10.7554/eLife.18683 
[56] Neugebauer, R., Hoek, H. W. and Susser, E. (1999). "Prenatal Exposure to Wartime Famine and Development of Antisocial Personality Disorder in Early Adulthood," JAMA 282, 455-462.

[57] Nimchimsky, E. A., Gilissen, E, Allman, J. M., Perl, D. P., Erwin, J. M., Hof, P. (1999). Neuronal Morphologic Type Unique to Humans and Great Apes. Proc Natl Acad Sci USA 96: 5268-5273.

[58] O'Leary, L., Hughes-McCormack, L., Dunn, K. and Cooper, S. A. (2018) Early Death and Causes of Death of People with Down Syndrome: A Systematic Review. J Appl Res Intellect Disabil, 31(5): 687-708. doi: 10.1111/jar.12446.

[59] Pantoja Zarza, L. and Diez Morrondo, C. (2014). Skeletal Deformities in Mucolipidosis III. Reumatol Clin. Vol. 10, 340-341.

[60] Passingham, R. (2009). How Good is the Macaque Monkey Model of the Human Brain? Current Opinion in Neurobiology, 19: 1-6.

[61] Plomin, R. and Deary, I. J. (2014). Genetics and Intelligence Differences: Five Special Findings. Molecular Psychiatry, 20, 98-108 (2015) http://dx.doi.org/10.1038/mp.2014.105 (Advance online pub).

[62] Plomin. R. and Von Stumm, S. (2018). The new genetics of intelligence. Nature Reviews Genetics, Vol. 19, 148-159.

[63] Premack, D. (2007). Human and Animal Cognition: Continuity and Discontinuity. PNAS (Proceedings of the National Academy of Sciences of the USA), Vol. 104, No. 35, 13861-13867.

[64] Preuss, T. M. and Coleman, G. Q. (2002). Cereb Cortex, 12: 671-691

[65] Prud'homme-Généreux, A. (2011). The Evolution of Human Skin Color. The National Center for Case Study Teaching in Science, University at Buffalo, State University of New York.

[66] Pruyn, M. L., Gartner, B. L. and Harmon, M. E. (2002). Respiratory Potential in Sapwood of Old versus Young Ponderosa Pine Trees in the Pacific Northwest. Tree Physiology, 22, 105-116.

[67] Rooij, W. H. Sr., Yonker, J. E., Painter, R. C. and Roseboom, T J. (2010). "Prenatal Under Nutrition and Cognitive Function in Late Adulthood," PNAS, Proceedings of the National Academy of Sciences USA 107 (2010), 16881-16886

[68] Roth, G. and Dicke, U. (2005) Evolution of the Brain and Intelligence. Trends in Cognitive Sciences, Vol. 9, No. 5, 250-257

[69] Roth, G. (2012) Is the Human Brain Unique? In: A. Fasolo (ed.) The Theory of Evolution and Its Impact, pp. 175-187. Springer-Verlag Italia 2012 DOI 10.1007/978-88-470-1974-4_11

[70] Ruff, C. C., Knauff, M., Fangmeier, T. and Spreer, J. (2003) Reasoning and Working Memory: Common and Distinct Neuronal Processes. Neuropsychologia, 41(9):1241-53 DOI: 10.1016/S00283932(03)00016-2

[71] Rumbaugh, D. M., Savage-Rumbaugh, E.S. and Taglialatela, J.P. (2009) Language: Nonhuman Animals. In: L. R. Squire (ed.) Encyclopedia of Neuroscience, Pages 367-371. Elsevier: Academic Press https://doi.org/10.1016/B978-008045046-9.01868-4.

[72] Rumbaugh, D. M. and Savage-Rumbaugh, E. S. (2001) Language and Animal Competencies. In: N. J. Smelser and P. B. Baltes (eds.) International Encyclopedia of the Social \& Behavioral Sciences, pp. 8281-8285. Elsevier: Pergamon https://doi.org/10.1016/B0-08-043076-7/01628-4.

[73] Ryskamp, Jessica L. (2010) Anencephaly: Concepts of Personhood, Ethical Questions, and Nursing Care. Senior Honors Theses. 199, Liberty University https://digitalcommons.liberty.edu/honors/199

[74] Savage, Jeanne E., Philip R. Jansen, Sven Stringer et al. (2018). Genome-wide association metaanalysis in 269,867 individuals identifies new genetic and functional links to intelligence. Nature Genetics, Vol. 50, 912-919

[75] Scholtens, L. H., Schmidt, R., de Reus, M. A. and van den Heuvel, M. P. (2014) Linking Macroscale Graph Analytical Organization to Microscale Neuroarchitectonics in the Macaque Connectome. Journal of Neuroscience, 34:12192-12205. https://doi.org/10.1523/JNEUROSCI.0752-14.2014

[76] Schörnig, M., Ju, X., Fast, L., Ebert, S., Weigert, A., Kanton, S., Schaffer, T., Kasri, N. N., Treutlein, B., Peter, B. M., Hevers, W. And Taverna, E. (2021) Comparison of Induced Neurons Reveals Slower Structural and Functional Maturation in Humans than in Apes. eLife, 10:e59323 DOI: $10.7554 /$ LLife.59323

[77] Schusterman, R. J. and Gisiner, R. (1988) Artificial Language Comprehension in Dolphins and Sea Lions: The Essential Cognitive Skills. The Psychological Record, 38, 311-348. https://doi.org/10.1007/BF03395027

[78] Seong, E., Yuan, L. \& Arikkath, J. (2015) Cadherins and Catenins in Dendrite and Synapse Morphogenesis. Cell Adhesion \& Migration, 9(3), 202-213, DOI: 10.4161/19336918.2014.994919 
[79] Shakeshaft, N. G., Trzaskowski, M., McMillan, A., Krapohl, E., Simpson, M. A., Reichenberg, A., Cederlöf, M., Larsson, H., Lichtenstein, P. and Plomin, R. (2015). Thinking Positively: The Genetics of High Intelligence. Intelligence, 48, 123-132.

[80] Skjaerven, R., Wilcox, A. J. and Lie, R. T. (1999) A Population-based Study of Survival and Childbearing among Female Subjects with Birth Defects and the Risk of Recurrence in Their Children. N Engl J Med, 340(14): 1057-62. doi: 10.1056/NEJM199904083401401

[81] Smrt, R. D. and Zhao, X. Y. (2010) Epigenetic Regulation of Neuronal Dendrite and Dendritic Spine Development. Front Biol (Beijing), 5(4):304-323. doi: 10.1007/s11515-010-0650-0.

[82] Teffer, K. and Semendeferi, K. (2012) Human Prefrontal Cortex: Evolution, Development, and Pathology. In: M. A. Hofman and D. Falk (Eds.) Progress in Brain Research, Vol. 195, 191-218, ISSN: 0079-6123 DOI: 10.1016/B978-0-444-53860-4.00009-X

[83] Testa-Silva, G., Verhoog, M. B., Linaro, D., de Kock, C. P., Baayen, J. C., Meredith, R. M., De Zeeuw, C. I., Giugliano, M. and Mansvelder, H. D. (2014) High Bandwidth Synaptic Communication and Frequency Tracking in Human Neocortex. PLoS Biology 12:e1002007. https://doi.org/10.1371/journal.pbio.1002007

[84] The Gorilla Foundation (2018). Project Koko. http://www.koko.org/project-koko

[85] Titz, C. and Karbach, J. (2014) Working Memory and Executive Functions: Effects of Training on Academic Achievement. Psychological Research, 78, 852-868. https://doi.org/10.1007/s00426-013$0537-1$

[86] Trzaskowski, M., Harlaar, N., Arden, R., Krapohl, E., Rimfeld, K., McMillan, A., Dale, P. S. And Plomin, R. (2014). Genetic influence on family socioeconomic status and children's intelligence. Intelligence, Vol. 42, 83-88.

[87] van den Heuvel, M. P., Scholtens, L. H., Feldman Barrett, L., Hilgetag, C. C. and de Reus, M. A. (2015) Bridging Cytoarchitectonics and Connectomics in Human Cerebral Cortex. Journal of Neuroscience, 35: 13943-13948. https://doi.org/10.1523/JNEUROSCI.2630-15.2015

[88] Wei, J. (2012). Great Inventions that Changed the World. New Jersey and Canada: John Wiley \& Sons, Inc.

[89] White, T. D., Asfaw, B., Beyene, Y., Haile-Selassie, Y., Lovejoy, C. O., Suwa, G. and WoldeGabriel, G. (2009). Ardipithecus ramidus and the Paleobiology of Early Hominids. Science, Vol. 326, No. 5949, pp. 64-86.

[90] Whiten, A. (2013). Monkeys, Apes, Imitation and Mirror Neurons. Cortex, 49, 2941-2943.

[91] Wisniewski, K. E. (1990) Down Syndrome Children Often Have Brain with Maturation Delay, Retardation of Growth, and Cortical Dysgenesis. Am J Med Genet Suppl, 7:274-81. doi: 10.1002/ajmg.1320370755.

[92] Yang, T. M. and Shadlen, M. N. (2007) Probabilistic Reasoning by Neurons. Nature, 447, 1075$1080 \mathrm{https}: / /$ doi.org/10.1038/nature05852

[93] Yin, Mei (2020) How Do the Black Hole and the Universe Form? International Journal of Psychosocial Rehabilitation, Vol. 24, No. 7, 243-247, ISSN: 1475-7192

(C) 2022 By AIRCC Publishing Corporation. This article is published under the Creative Commons Attribution (CC BY) license. 